\title{
Determination of Fluid Viscosity Coefficient Using jetAudio and Subtitle Edit
}

\author{
Haris Rosdianto ${ }^{1}$, Emi Sulistri ${ }^{2}$, Anis Nazihah Mat Daud ${ }^{3}$ \\ STKIP Singkawang, Indonesia ${ }^{1,2}$, Universiti Teknologi Malaysia, Malaysia ${ }^{3}$ \\ harisrosdianto@yahoo.com¹, sulistriemi@gmail.com ${ }^{2}$, anisnmd@yahoo.co.uk ${ }^{3}$ \\ Received: August $19^{\text {th }}, 2019$. Revised: September $5^{\text {th }}, 2019$. Accepted: September $9^{\text {th }}, 2019$
}

\author{
Keywords: \\ Viscosity Coefficient; Coil \\ Sensors; jetAudio; Subtitle \\ Edit
}

\begin{abstract}
The purpose of this study is to produce an experimental design for determining the viscosity coefficient using jetAudio and Subtitle Edit software, and determining the value of the fluid viscosity coefficient by using this experimental design. In this study, the type of fluid used is packaged cooking oil, and the object used is a magnetic ball. The method proposed by the authors to measure the travel time of the magnetic ball in cooking oil is by using the combination of coil sensors, jetAudio, and Subtitle Edit. JetAudio software will record magnetic induction traces as the magnetic ball passes the coils into audio format, Subtitle Edit software is used to determine travel time of the magnetic ball based on jetAudio recording data. The results of this study are jetAudio and Subtitle Edit can be used in fluid viscosity coefficient experiments. The value of the cooking oil viscosity coefficient obtained from this study is 0,561431096 Pa.s.
\end{abstract}

\section{INTRODUCTION}

Practicum activities play a very large and effective role in building concept understanding, verifying the truth of concepts, and fostering students' science process skills in physics [1]. Practical activities can also train students' skills in observing, predicting, formulating hypotheses, designing experiments, interpreting data, until at the conclusion stage. But the problem that occurred lately, there are still many schools that do not have adequate laboratory facilities and infrastructure. This situation also occurred in Singkawang City, West Kalimantan.

From observations and interviews at 5 state high schools in Singkawang City, it was found that $30 \%$ of schools did not have laboratory, $46 \%$ of equipment conditions are inadequate and totally damaged, $25 \%$ of teachers have difficulty doing laboratory activity, and around $74 \%$ of teachers rarely do laboratory activity. In addition to having an impact on teachers' ability to do laboratoty activity, inadequate equipment conditions also have an impact on students' abilities, so students have difficulty in understanding physics concepts. One of the practicum tools with these conditions is in the practicum for determining the fluid viscosity coefficient. Stopwatch is usually used in this practicum as the time meter. Because time measurement is done manually, the results obtained are less accurate. 
Along with the development of technology, many practicum activities have used technology applications to obtain data more accurately. The use of technology to observe the viscosity phenomenon has been carried out by several researchers, among them by using tracker video analysis, as well as freewave 3 software that is applied in learning physics. Utilization of technology in the development of practicum tools makes it easy for teachers and students to do laboratory activity.

Determination of the fluid viscosity coefficient can be done by various methods [2-6]. One method that can be used in determining viscosity is the falling ball method. Initially, the velocity of the ball dropped into a liquid will increase. But at a certain moment, the ball will experience terminal velocity, where in this state the object's gravity is equal to the amount between Archimedes and Stoke's force. In practice, determining the value of viscosity begins with determining the terminal velocity.

The falling ball method with two coils as a detection sensor can be used in determining the viscosity of lubricant [7]. Where the two coils are connected to the oscilloscope and the results are processed using freewave3 software. By giving a sinusoidal signal to the coil and dropping the ball into the tube containing the fluid, data about the voltage changing when the ball passes through the coil will be obtained. From the data recorded in the freewave 3 software, the terminal velocity of the ball can be calculated. The terminal velocity of the ball is determined by calculating the gradient from the graph of distance against time [8-12].

The value of fluid viscosity can also be determined by using Tracker video analysis software [13,14]. Starting by calculating terminal velocity, then determining the viscosity value of cooking oil and oil by using Tracker video analysis software. The marble dropped into the fluid will be analyzed, and the terminal velocity can be obtained. Then the value of fluid viscosity can be calculated using Stokes equation. From the analysis and calculation, it was found that the terminal velocity of marble is inversely proportional to the viscosity of fluid. If the viscosity of the fluid increases, the terminal velocity of the marble decreases [15-21].

Determination of viscosity can also be done by using the falling ball method utilizing UGN3503 hall effect sensor as an iron ball detection sensor as it passes through the fluid and causes the magnetic field of this sensor to change because the sensor is blocked by an iron ball magnet, so the magnetic field changed to output voltage [22]. This generated voltage will be processed and recorded as the travel time by the Atmega 8 microcontroller. The value of viscosity is determined by measuring the ball's travel time, density of the ball and fluid, and the distance traveled by the ball. Determination of the value of viscosity is mostly done to find alternative methods that are easily obtained and used, and have better accuracy compared to experiments that using stopwatch.

Referring to previous studies and needs analysis in schools, the purpose of this study is to develop a precise and accurate practicum tool with software that is easily obtained and used, namely jetAudio and Subtitle Edit. It is hoped that this developed practicum tools can become as a alternative media in learning physics and able to help students to become more skilled and qualified in laboratory activities. JetAudio is a software that can read audio and video files. Although jetAudio has the same function as Winamp, RealPlayer, and similar-function software, the features of a software certainly have their own advantages [23]. JetAudio has features that can rip DVD files to VCD files, create files in the form of audio CDs, change the format of audio and video files, or it can also be used for recording.

Subtitle Edit is an open-source software that is used to create, edit, adjust or synchronize subtitles for videos. This software can be used to visualize audio waves. This software uses VLC, MPC-HC, Mpv or DirectShow to play videos [24]. 


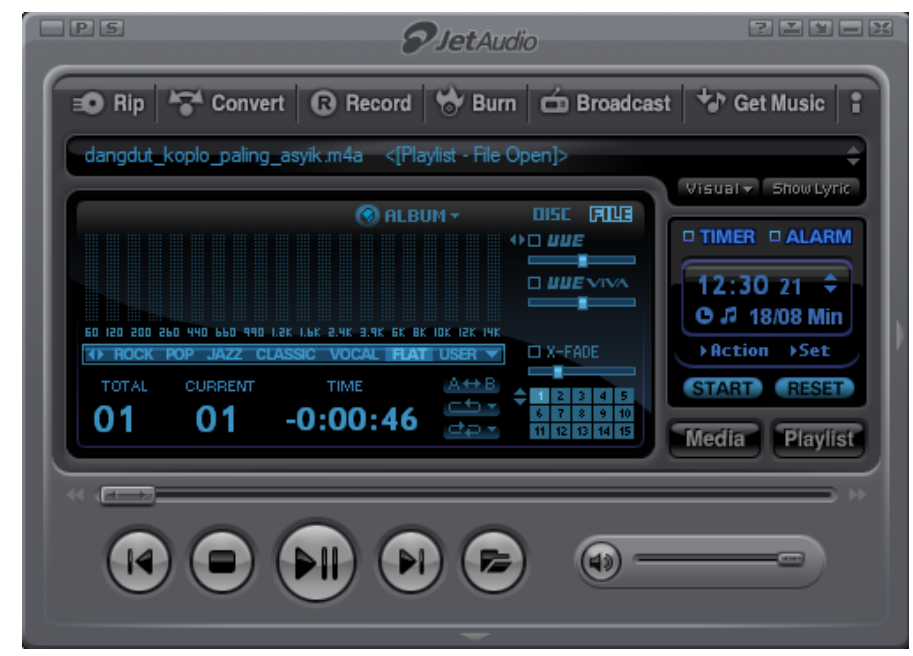

Fig 1. Display of jetAudio software

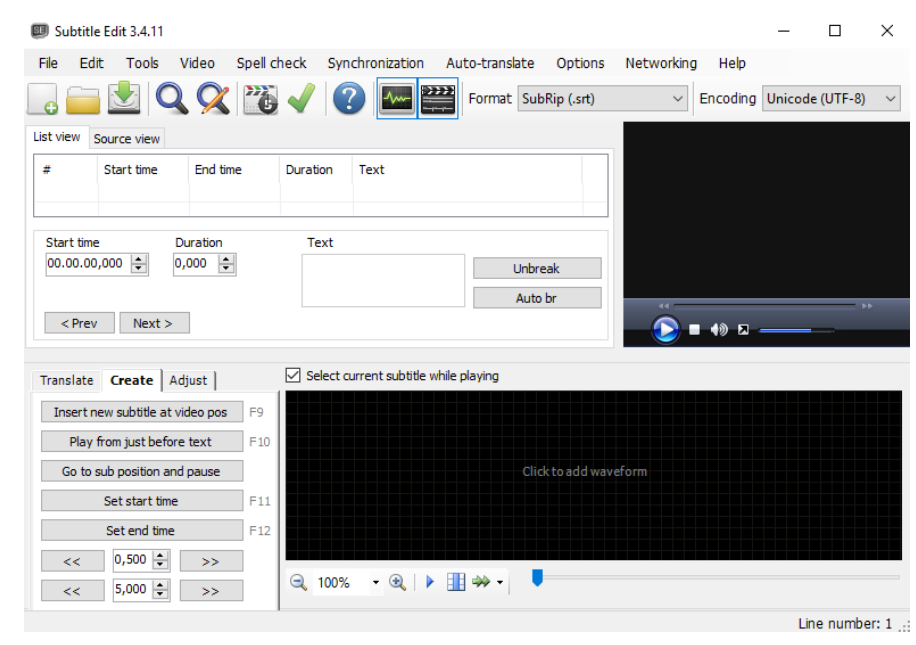

Fig 2. Display of Subtitle Edit software

What is new and different from this study with similar studies that have been done before is as follows: 1) jetAudio and Subtitle Edit is free and easily obtained and used but has the same function as freewave3. 2) jetAudio and Subtitle Edit have high accuracy when compared to other free software, such as Tracker video analysis. 3) Based on the function in obtaining time data, jetAudio and Subtitle Edit are no less rigorous with UGN3503 hall effect sensor. This makes the use of jetAudio and Subtitle Edit is suitable for schools that have limitations because the price of the Atmega8 microcontroller is quite expensive.

The main question in this study is can the practicum tool for determining the viscosity coefficient by using jetAudio and Subtitle Edit be implemented in school physics practicum? So the purpose of this study is to design a practicum tool for determining the viscosity coefficient by using jetAudio and Subtitle Edit that is suitable for use in schools.

\section{METHOD}

The tools and materials used in this study are: 1) coil wire, 2) digital scales, 3) crocodile pins, 4) rulers, 5) calipers, 6) connecting cables, 7) PVC tube, 8) magnetic ball, 9 ) audio plugs, and 10) computer. 


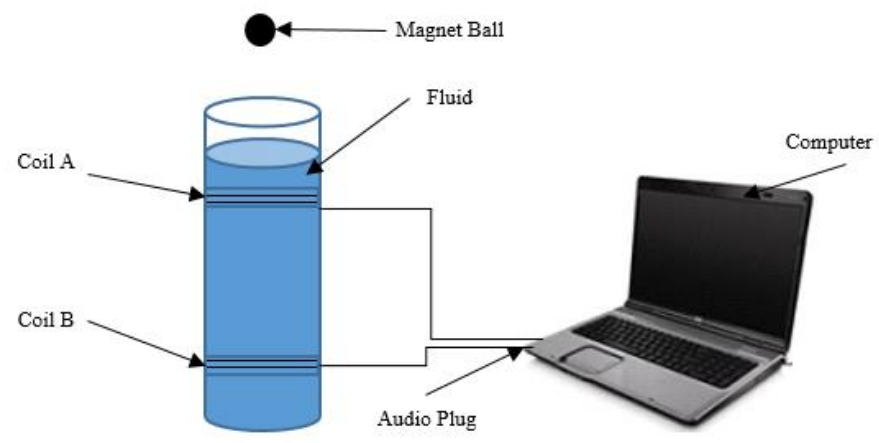

Fig 3. Schema of the Experiment

The procedure of this experiment: 1) determine the mass and diameter of the magnetic ball, 2) calculate the volume of the magnetic ball, 3) calculate the density of the magnetic ball, 4) determine the mass of cooking oil, 5) measure the volume of cooking oil, 6) calculate the density of cooking oil, 7) arrange the tool as shown in Figure 3,8) set the distance between coils, 9) drop the magnetic ball into the tube and record the magnetic induction trace using jetAudio, 10) determine the travel time based on jetAudio recording data using Subtitle Edit, 11) calculate the viscosity coefficient of cooking oil using equation 1,12 ) repeat steps $8-11$ by varying the distance between coils, which is varied by $15 \mathrm{~cm}, 20 \mathrm{~cm}, 25 \mathrm{~cm}$ and $30 \mathrm{~cm}$.

Following is the equation used to calculate the fluid viscosity coefficient,

$$
\eta=\frac{\frac{2}{9} r^{2} g\left(d_{b}-d_{f}\right)}{v}
$$

where $\eta$ is the fluid viscosity coefficient, $\mathrm{r}$ is adalah the radius of the ball, $\mathrm{g}$ is acceleration of gravity, $\mathrm{db}$ is the density of the ball, $\mathrm{df}$ is the density of the fluid, and $\mathrm{v}$ is terminal velocity $[25,26]$.

\section{RESULTS AND DISCUSSIONS}

Before the experimental steps to determine the coefficient of cooking oil viscosity, some parameters must be measured as a support in data analysis. The measurement results of these parameters can be seen in table 1.

Table 1. Technical specification of tools and materials

\begin{tabular}{cc}
\hline Measured Parameter & Values and Units \\
\hline Mass of magnet ball & $0.008 \mathrm{~kg}$ \\
Diameter of magnet ball & $0.014 \mathrm{~m}$ \\
Volume of magnet ball & $1.43 \times 10-6 \mathrm{~m}^{3}$ \\
Density of magnet ball & $5,568.103 \mathrm{~kg} / \mathrm{m}^{3}$ \\
Mass of cooking oil & $0.9 \mathrm{~kg}$ \\
Volume of cooking oil & $0.001 \mathrm{~m}$ \\
Density of cooking oil & $900 \mathrm{~kg} / \mathrm{m}^{3}$ \\
Acceleration of gravity & $9.8 \mathrm{~m} / \mathrm{s}^{2}$ \\
\hline
\end{tabular}

Then the experiment to determine the viscosity coefficient of cooking oil was carried out. Data analysis for the distance of $15 \mathrm{~cm}$ can be seen in table 2 , for the distance of $20 \mathrm{~cm}$ can be seen in table 3 , for the distance of $25 \mathrm{~cm}$ can be seen in table 4, and for the distance of $30 \mathrm{~cm}$ can be seen in table 5 . 
JIPF, Vol. 4 No. 2, September 2019

Table 2. Data analysis for distance $=15 \mathrm{~cm}$

\begin{tabular}{cccc}
\hline No. & $\boldsymbol{t}(\mathbf{s})$ & $\boldsymbol{v}\left(\mathbf{m} / \mathbf{s}^{\mathbf{2}}\right)$ & $\boldsymbol{\eta}$ (Pa.s) \\
\hline 1 & 0.171 & 0.877192982 & 0.567877838 \\
2 & 0.168 & 0.892857143 & 0.557915069 \\
3 & 0.168 & 0.892857143 & 0.557915069 \\
4 & 0.165 & 0.909090909 & 0.5479523 \\
5 & 0.17 & 0.882352941 & 0.564556915 \\
6 & 0.167 & 0.898203593 & 0.554594146 \\
7 & 0.172 & 0.872093023 & 0.571198761 \\
8 & 0.166 & 0.903614458 & 0.551273223 \\
9 & $0, .169$ & 0.887573964 & 0.561235992 \\
10 & 0.17 & 0.882352941 & 0.564556915 \\
\hline & & $\eta_{\text {average }}=$ & $\mathbf{0 . 5 5 9 9 0 7 6 2 3}$ \\
\hline
\end{tabular}

Table 3. Data analysis for distance $=20 \mathrm{~cm}$

\begin{tabular}{cccc}
\hline No. & $\boldsymbol{t}(\mathbf{s})$ & $\boldsymbol{v}\left(\mathbf{m} / \mathbf{s}^{\mathbf{2}}\right)$ & $\boldsymbol{\eta}$ (Pa.s) \\
\hline 1 & 0.235 & 0.85106383 & 0.585312684 \\
2 & 0.223 & 0.896860987 & 0.555424376 \\
3 & 0.241 & 0.829875519 & 0.600256837 \\
4 & 0.232 & 0.862068966 & 0.577840607 \\
5 & 0.225 & 0.8888888889 & 0.560405761 \\
6 & 0.216 & 0.925925926 & 0.537989531 \\
7 & 0.222 & 0.900900901 & 0.552933684 \\
8 & 0.235 & 0.85106383 & 0.585312684 \\
9 & 0.237 & 0.843881857 & 0.590294068 \\
10 & 0.227 & 0.881057269 & 0.565387146 \\
\hline & & $\boldsymbol{\eta}_{\text {average }}=$ & $\mathbf{0 . 5 7 1 1 1 5 7 3 8}$ \\
\hline
\end{tabular}

Table 4. Data analysis for distance $=25 \mathrm{~cm}$

\begin{tabular}{cccc}
\hline No. & $\boldsymbol{t}(\mathbf{s})$ & $\boldsymbol{v}\left(\mathbf{m} / \mathbf{s}^{\mathbf{2}}\right)$ & $\boldsymbol{\eta}$ (Pa.s) \\
\hline 1 & 0.284 & 0.88028169 & 0.565885284 \\
2 & 0.275 & 0.909090909 & 0.5479523 \\
3 & 0.281 & 0.889679715 & 0.559907623 \\
4 & 0.277 & 0.902527076 & 0.551937407 \\
5 & 0.274 & 0.912408759 & 0.545959746 \\
6 & 0.28 & 0.892857143 & 0.557915069 \\
7 & 0.279 & 0.896057348 & 0.555922515 \\
8 & 0.282 & 0.886524823 & 0.561900176 \\
9 & 0.276 & 0.905797101 & 0.549944853 \\
10 & 0.283 & 0.883392226 & 0.56389273 \\
\hline & & $\eta_{\text {average }}=$ & $\mathbf{0 . 5 5 6 1 2 1 7 7}$ \\
\hline
\end{tabular}


Determination of Fluid Viscosity Coefficient Using jetAudio and Subtitle Edit Haris Rosdianto, Emi Sulistri, Anis Nazihah Mat Daud

Table 5. Data analysis for distance $=30 \mathrm{~cm}$

\begin{tabular}{cccc}
\hline No. & $\boldsymbol{t}(\mathbf{s})$ & $\boldsymbol{v}\left(\mathbf{m} / \mathbf{s}^{\mathbf{2}}\right)$ & $\boldsymbol{\eta}$ (Pa.s) \\
\hline 1 & 0.342 & 0.877192982 & 0.567877838 \\
2 & 0.337 & 0.890207715 & 0.55957553 \\
3 & 0.335 & 0.895522388 & 0.556254607 \\
4 & 0.341 & 0.879765396 & 0.566217376 \\
5 & 0.329 & 0.911854103 & 0.546291838 \\
6 & 0.339 & 0.884955752 & 0.562896453 \\
7 & 0.328 & 0.914634146 & 0.544631377 \\
8 & 0.333 & 0.900900901 & 0.552933684 \\
9 & 0.337 & 0.890207715 & 0.55957553 \\
10 & 0.343 & 0.874635569 & 0.569538299 \\
\hline & & $\eta_{\text {average }}=$ & $\mathbf{0 . 5 5 8 5 7 9 2 5 3}$ \\
\hline
\end{tabular}

From table 2, from experiments conducted 10 times, it appears that the travel time of the magnetic ball in cooking oil is relatively constant, so that the terminal velocity is relatively constant. The measured viscosity coefficient of cooking oil is also relatively constant. So for the distance of $15 \mathrm{~cm}$, the value of the cooking oil viscosity coefficient on average is obtained by $0.559907623 \mathrm{~Pa}$.s.

From table 3, from experiments conducted 10 times, it appears that the travel time of the magnetic ball in cooking oil is relatively constant, so that the terminal velocity is relatively constant. The measured viscosity coefficient of cooking oil is also relatively constant. So for the distance of $20 \mathrm{~cm}$, the value of the cooking oil viscosity coefficient on average is obtained by 0.571115738 Pa.s.

From table 4, from experiments conducted 10 times, it appears that the travel time of the magnetic ball in cooking oil is relatively constant, so that the terminal velocity is relatively constant. The measured viscosity coefficient of cooking oil is also relatively constant. So for the distance of $25 \mathrm{~cm}$, the value of the cooking oil viscosity coefficient on average is obtained by 0.55612177 Pa.s.

From table 5, from experiments conducted 10 times, it appears that the travel time of the magnetic ball in cooking oil is relatively constant, so that the terminal velocity is relatively constant. The measured viscosity coefficient of cooking oil is also relatively constant. So for the distance of $30 \mathrm{~cm}$, the value of the cooking oil viscosity coefficient on average is obtained by $0.558579253 \mathrm{~Pa}$.s.

Table 6. Recapitulation of data analysis for each distance

\begin{tabular}{cc}
\hline Distance $(\mathbf{c m})$ & $\boldsymbol{\eta}$ (Pa.s) \\
\hline 15 & 0.559907623 \\
20 & 0.571115738 \\
25 & 0.55612177 \\
30 & 0.558579253 \\
\hline $\boldsymbol{\eta}_{\text {average }}=$ & $\mathbf{0 . 5 6 1 4 3 1 0 9 6}$ \\
\hline $\boldsymbol{S} \boldsymbol{D}=$ & $\mathbf{0 . 0 0 6 6 4 4 1 7 5}$ \\
\hline
\end{tabular}

Table 6 contains the recapitulation results from data analysis for each distance. The value of the cooking oil viscosity coefficient from the measurement results for each distance is relatively constant, this can be seen from the small standard deviation value, which is 0.006644175 . On average, the value of the cooking oil viscosity coefficient can be determined at 0.561431096 Pa.s. So it can be stated that the experimental design of determining fluid viscosity coefficient using jetAudio software and Subtitle Edit can be implemented in physics learning in schools. 


\section{CONCLUSION}

From the results of data processing, the value of the cooking oil viscosity coefficient is 0.561431096 Pa.s. This shows that jetAudio and Subtitle Edit software can be used to obtain the travel time data of the magnetic ball, which is then processed to calculate the value of the fluid viscosity coefficient. So it can be concluded that this experimental design can be implemented in school physics practicum.

\section{ACKNOWLEDGMENTS}

The authors would like to thank Directorate General of Research and Development Strengthening, Ministry of Research, Technology and Higher Education who has provided research grants with contract number: 619/L11/KM/2019. The authors also would like to thank STKIP Singkawang for supporting this research.

\section{REFERENCES}

[1] Koretsky, M., Kelly, C., \& Gummer, E. (2011). Student perceptions of learning in the laboratory: Comparison of industrially situated virtual laboratories to capstone physical laboratories. Journal of Engineering Education, 100(3): 540-573.

[2] Rudyak, V. Y., Dimov, S. V., \& Kuznetsov, V. V. (2013). On the dependence of the viscosity coefficient of nanofluids on particle size and temperature. Technical Physics Letters, 39(9): 779782.

[3] Greaves, M. (2012). Pressure viscosity coefficients and traction properties of synthetic lubricants for wind turbine gear systems. Lubrication Science, 24(2): 75-83.

[4] Bair, S. (2013). Comments on "pressure-viscosity coefficient of vegetable oils" by Biresaw and Bantchev. Tribology Letters, 52(2): 351-353.

[5] Akimoto, H., Nagai, K., \& Sakurai, N. (2012). Viscosity measurement by the free vibrations of homogeneous viscoelastic sphere. Journal of Applied Mechanics, 79(4): 041002.

[6] Romero, C. M., Rodríguez, D. M., Ribeiro, A. C., \& Esteso, M. A. (2017). Effect of temperature on the partial molar volume, isentropic compressibility and viscosity of DL-2-aminobutyric acid in water and in aqueous sodium chloride solutions. The Journal of Chemical Thermodynamics, 104: 274-280.

[7] Shanti. M. R. S., (2014). Pembuatan Media Pembelajaran Pengukuran Viskositas Dengan Menggunakan Viskometer Dua Kumparan Dan Freewave3. Jurnal Pendidikan Fisika Indonesia, 10(1): 28-35.

[8] Jóźwiak, M., Tyczyńska, M., \& Bald, A. (2013). Viscosity of Urea in the Mixture of N, NDimethylformamide and Water. Journal of Chemical \& Engineering Data, 58(2): 217-224.

[9] Patil, P. D., Shaikh, V. R., Gupta, G. R., Hundiwale, D. G., Borse, A. U., \& Patil, K. J. (2016). Studies of viscosity coefficient and expansivity properties of aqueous solutions of ethylene glycol and polyethylene glycols at $293.15,298.15$ and $303.15 \mathrm{~K}$ and at ambient pressure. Journal of Solution Chemistry, 45(6): 947-969.

[10] Mannarelli, M., Manuel, C., \& Tolos, L. (2013). Phonon contribution to the shear viscosity of a superfluid Fermi gas in the unitarity limit. Annals of Physics, 336: 12-35.

[11] Siddiqui, N., \& Ahmad, A. (2013). A study on viscosity, surface tension and volume flow rate of some edible and medicinal oils. Int. J. Sci. Environ. Technol, 2: 1318-1326.

[12] Paredes, X., Fandiño, O., Pensado, A. S., Comuñas, M. J. P., \& Fernández, J. (2012). Pressureviscosity coefficients for polyalkylene glycol oils and other ester or ionic lubricants. Tribology Letters, 45(1): 89-100.

[13] Hantoro, B., \& Suharno. (2014). Menyelidiki Hubungan Kecepatan Terminal Dan Viskositas Zat Cair dengan Video Analisis Tracker . Prosiding Pertemuan Ilmiah XXVIII HFI Jateng \& DIY, Yogyakarta, 26 April 2014: 35-37. 
[14] Mariani. F, et al. (2015). Penerapan Analisis Video Tracker dalam Pembelajaran Fisika SMA Untuk Menentukan Nilai Koefisien Viskositas Fluida. Prosiding Simposium Nasional Inovasi dan Pembelajaran Sains 2015 (SNIPS 2015): 333-336.

[15] Llovell, F., Marcos, R. M., \& Vega, L. F. (2013). Free-volume theory coupled with soft-SAFT for viscosity calculations: comparison with molecular simulation and experimental data. The Journal of Physical Chemistry B, 117(27): 8159-8171.

[16] Price, H. C., Murray, B. J., Mattsson, J., O'sullivan, D., Wilson, T. W., Baustian, K. J., \& Benning, L. G. (2014). Quantifying water diffusion in high-viscosity and glassy aqueous solutions using a Raman isotope tracer method. Atmospheric Chemistry and Physics, 14(8): 3817-3830.

[17] Ghaderi, F., Ghaderi, A. H., Najafi, B., \& Ghaderi, N. (2013). Viscosity prediction by computational method and artificial neural network approach: The case of six refrigerants. The Journal of Supercritical Fluids, 81: 67-78.

[18] Koralewski, J. (2011). Influence of hydraulic oil viscosity on the volumetric losses in a variable capacity piston pump. Polish Maritime Research, 18(3): 55-65.

[19] Cidade, M. T., Fernández, M., \& Santamaria, A. (2012). Pressure-volume-temperature results and pressure dependency on the viscosity of three liquid crystalline cellulose derivatives. Liquid Crystals, 39(1): 115-120.

[20] Oghaz, N. M., Ghiamati, E., Haghighi, B., Nasrabad, A. E., Papari, M. M., \& Bamdad, M. (2012). A new approach to estimate viscosity in dilute and dense pure fluid states by using generalized friction theory based on pair interaction potential energy functions. Journal of Molecular Liquids, 165: 55-62.

[21] Prasad, K. V., Pal, D., Umesh, V., \& Rao, N. P. (2010). The effect of variable viscosity on MHD viscoelastic fluid flow and heat transfer over a stretching sheet. Communications in Nonlinear Science and Numerical Simulation, 15(2): 331-344.

[22] Ramadhan, D., Serevina, V., \& Raihanati. (2016) Pengembangan Alat Praktikum Viskometer Metode Bola Jatuh Bebas Berbasis Sensor Efek Hall UGN3503 sebagai Media Pembelajaran Fisika. Prosiding Seminar Nasional Fisika (E-Journal) SNF2016, 5(1): 7-10.

[23] Mulyono, S., \& Agus, S. (2010). Kumpulan Software Pilihan Paling Dicari. MediaKita, 2008.

[24] Lynch, N. (2010). An excellent app to edit subtitles.

[25] Vong, S. W., Yang, T., \& Zhu, C. (2003). Compressible Navier-Stokes equations with degenerate viscosity coefficient and vacuum (II). Journal of Differential Equations, 192(2): 475-501.

[26] Lei, Z., \& Lin, F. H. (2011). Global mild solutions of Navier-Stokes equations. Communications on Pure and Applied Mathematics, 64(9): 1297-1304. 